\title{
Effect of annealing atmosphere on microstructure, optical and electronic properties of spray-pyrolysed In-doped $\mathrm{Zn}(\mathrm{O}, \mathrm{S})$ thin films
}

\author{
MARGI JANI, DHYEY RAVAL, RANJAN KUMAR PATI, INDRAJIT MUKHOPADHYAY \\ and ABHIJIT RAY* \\ Solar Research and Development Center, School of Solar Energy, Pandit Deendayal Petroleum University, \\ Gandhinagar 382007, India \\ *Author for correspondence (abhijit.ray1974@gmail.com)
}

MS received 2 March 2017; accepted 2 May 2017; published online 5 February 2018

\begin{abstract}
Spray-pyrolysed zinc oxy-sulphide $\mathrm{Zn}(\mathrm{O}, \mathrm{S})$ has been doped with varying concentrations of indium (In) to improve its electrical and optical properties for possible application as buffer layer in thin film solar cells. The In-doping in $\mathrm{Zn}(\mathrm{O}, \mathrm{S})$ is found to change the electron carrier concentration from $10^{19}$ to $10^{18} \mathrm{~cm}^{-3}$ and a subsequent annealing in argon atmosphere is found to improve its electrical conductivity. Moreover, annealing in air atmosphere reduces the carrier concentration to a range of $10^{13}-10^{15} \mathrm{~cm}^{-3}$ making it useful as a buffer layer. The reduction in degeneracy of In-doped $\mathrm{Zn}(\mathrm{O}, \mathrm{S})$ is desirable for its application as buffer material, whereas annealing in argon makes it suitable as electron membrane (window layer) in thin film solar cell.
\end{abstract}

Keywords. Buffer layer; window layer; thin film solar cell; doping; electrical properties.

\section{Introduction}

Zinc oxide $(\mathrm{ZnO})$ is one of the promising and nontoxic compounds with widespread optoelectronic [1], photonic [2] and photovoltaic [3] applications due to its excellent stability, wide band gap $(3.3 \mathrm{eV})$ and ease of doping. Although, native defects in $\mathrm{ZnO}$, such as oxygen vacancies and zinc interstitials are responsible for its $n$-type conductivity, cation or anion site isovalent doping can drastically change its electronic and optical properties [4]. In many cases, such dopants are responsible for modifying the electronic structure of the host lattice leading to a variation in its electrical and optical properties. Doping of $\mathrm{ZnO}$ can also be achieved by creating non-stoichiometry in the system $[5,6]$. Such a doping by substituting oxygen atoms with chalcogens, such as $\mathrm{S}$, Se or Te are expected to significantly modify the electrical and optical properties due to large electronegativity and ionic radii differences of this dopant atoms relative to oxygen [7-9]. In this aspect, $\mathrm{Zn}(\mathrm{O}, \mathrm{S})$, a solid solution of $\mathrm{ZnO}$ and $\mathrm{ZnS}$, was proved to be a good candidate for band gap modulation [10]. The band gap energies of $\mathrm{ZnO}$ and $\mathrm{ZnS}$ lead to an unfavourable electronic properties for $\mathrm{Zn}(\mathrm{O}, \mathrm{S})$, when used as buffer layer in heterojunction solar cells, causes a band offset with its heterojunction partner. This can be addressed by a careful choice of the alloy composition [11]. Generally, maximization of the open circuit voltage in a solar cell depends on the band bending of the absorber layer, which determines the charge neutrality, doping concentration and band discontinuity in the $n / p$ and $n / n^{+}$interfaces. Moreover, the performance of the cell depends on good ohmic contact between the buffer and the transparent conductive oxide (TCO) layers and the transport properties of the heterojunction depend on the interface electronic properties [12]. In general, for buffer layer, a carrier concentration in the range of $10^{14}-10^{16} \mathrm{~cm}^{-3}$ is desirable, as the higher carrier concentration leads to higher carrier recombination in the absorber [13]. However, the $\mathrm{Zn}(\mathrm{O}, \mathrm{S})$ layer with a higher carrier concentration can be effective for the portion of the buffer layer closer to the TCO to reduce its contact (and hence series) resistance [14,15]. It is known that a graded buffer layer $\left(n / n^{++}\right)$with increasing carrier concentration from the absorber to the TCO layer enhances the carrier collection efficiency in the thin film solar cells. Indium, aluminum and gallium are well-known dopants to increase carrier concentration, which can improve and/or control the electrical conductivity of $\mathrm{ZnO}$ for its application as TCO [16-18]. These dopants act as a donor when it occupies a substitutional position for $\mathrm{Zn}^{2+}$ cation or an interstitial position in the lattice [19]. It is reported that the resistivity of $\mathrm{ZnO}$ can be lowered to a value of $4.7 \times 10^{-3}$ and $2.6 \times 10^{-4} \Omega \mathrm{cm}$ by Al (lower ionic radii compared to $\mathrm{Zn}^{2+}$ ) and $\mathrm{Ga}$ (larger ionic radii than $\mathrm{Zn}^{2+}$ ) dopings, respectively $[20,21]$. In the case of $\mathrm{ZnO}$ used in solar cells as buffer layer and in some diodes fabrication, the dopants with high value of ionic radii are important to reduce the ionic diffusion towards the junction and creating non-radiative recombination centres. In this respect, In is a better choice as dopant for cation 
site in $\mathrm{ZnO}$ over the other competitors, such as $\mathrm{B}, \mathrm{Al}$ and Ga.

In the present work, In-doped $\mathrm{Zn}(\mathrm{O}, \mathrm{S})$ thin films were obtained by using simple spray deposition. The spray deposition technique has certain advantages over the other solutionbased non-vacuum techniques, such as sol-gel methods [22]. Despite the simplicity to fabricate doped transparent conductive materials [23], sol-gel techniques are unable to arrive at its full industrial potential due to some limitations, e.g., weak bonding, low-wear resistance, high permeability and difficulty in controlling porosity. The sol-gel technique is also substrate-dependent, and the thermal expansion mismatch limits the wide applications of sol-gel technique, whereas above problems are largely mitigated in the spray pyrolysis and hence, further adopted in our study. The spray process was followed by annealing to improve its morphology, crystallinity and electronic properties. The investigation shows that air annealing can be useful to reduce the carrier concentration to a level, appropriate for its use as a buffer layer, while an annealing in argon atmosphere is useful to improve its electrical conductivity. A detailed investigation on the role of In doping and annealing condition in $\mathrm{ZnO}$ over its microstructure, optical and electronic properties is presented.

\section{Experimental}

In-doped $\mathrm{Zn}(\mathrm{O}, \mathrm{S})$ thin films were deposited by spray deposition method, where a solution containing precursors of indium chloride $\left(\mathrm{InCl}_{3}\right)$, zinc chloride $\left(\mathrm{ZnCl}_{2}\right)$ (Acros, $98.5 \%$ purity) and thiourea $\left(\mathrm{CH}_{4} \mathrm{~N}_{2} \mathrm{~S}\right)$ (Merck, $99 \%$ purity) were dissolved in the mixture of isopropyl alcohol and de-ionized water at a volume ratio of 70:30\%. To achieve the In-doping, $\mathrm{InCl}_{3}$ was used in different precursor weight percentages of 1,3 and $5 \%$ of zinc precursor concentration. Thiourea was used as a source of sulphur in $\mathrm{Zn}(\mathrm{O}, \mathrm{S})$, the weight fraction of which was $20 \mathrm{wt} \%$ that produces a minimum band gap in $\mathrm{Zn}(\mathrm{O}, \mathrm{S})$. The prepared solution was sprayed by a compressed air-assisted system on a clean soda lime glass substrate, which was placed above a controlled heating plate as described elsewhere [10]. Annealing was performed in air and argon (Ar) atmosphere at $370^{\circ} \mathrm{C}$ for $1 \mathrm{~h}$ in a quartz tube furnace (MTI, EQ-OTF$1200 \mathrm{X})$. Usually, at a temperature below $350^{\circ} \mathrm{C}$, the pyrolysis is incomplete and a phase separation occurs at temperature above $400^{\circ} \mathrm{C}$.

The crystal structure of the prepared films was investigated by using X-ray diffraction (XRD) pattern recorded by an X-ray diffractometer (PANalytical, model X'Pert PRO) with $\mathrm{CuK} \alpha$ radiation $(\lambda)$ using a Ni filter in thin film measurement mode. Morphological characterization of the samples was performed by a field-emission scanning electron microscope (FESEM) (Zeiss, model Ultra 55). The high resolution (HR)transmission electron micrograph (TEM) was performed in a TEM microscope (Jeol, JEM 2100). The optical band gap, transmittance and absorbance coefficient were estimated by using UV-Vis spectrophotometer (Simadzu, model
UV-2600) in the spectral range of 350-1400 $\mathrm{nm}$. The surface investigation was made by atomic force microscopy (AFM) using contact mode. The electrical conductivity and carrier concentrations were measured by a Hall measurement system (Ecopia, model HMS-3000).

\section{Results and discussion}

\subsection{Structural and morphological studies}

The structural studies are made in the In-doped $\mathrm{Zn}(\mathrm{O}, \mathrm{S})$ with an optimum $20 \mathrm{wt} \%$ of sulphur. This optimization was done on the basis of optical studies to determine their band gap, which was discussed in detail in the subsequent section. The XRD patterns of undoped and In-doped samples of $\mathrm{Zn}(\mathrm{O}, \mathrm{S})$ with a fixed concentration of sulphur $(20 \mathrm{wt} \%)$ is shown in figure 1. All the films are found to crystallize in pure hexagonal wurtzite structure with (100), (002) and (101) as the principal planes (JCPDS, 36-1451). No unreacted $\mathrm{In}_{2} \mathrm{O}_{3}$ or no phase separation into $\mathrm{ZnO}$ and $\mathrm{ZnS}$ were observed from the spectra, except a peak shift, which was observed towards lower $2 \theta$ due to the lattice expansion originated from the substitution of oxygen by sulphur. The peak profile fitting shows that the estimated lattice constants increase from $a=b=3.25 \AA$ and $c=5.21 \AA$ in $\mathrm{ZnO}$ to $a=b=3.26 \AA$ and $c=5.22 \AA$ in the $\mathrm{Zn}(\mathrm{O}, \mathrm{S})$ that agrees well with previous reports $[10,15]$. A preferred orientation along the $(002)$ direction was evolved for indium concentration up to $3 \mathrm{wt} \%$, giving a grain growth perpendicular to the substrate surface. This observation agrees well with other doped and annealed $\mathrm{ZnO}$ films made from solution routes [24,25]. The intensity ratio, $I_{(002)} /\left(I_{(002)}+I_{(100)}\right)$, suggests that the $c$-axis orientation of the grains changes with lower to higher In-doping concentration (as shown in table 1). This ratio decreases for higher indium content. This intermediate increase of (002) texture was reported in In: $\mathrm{ZnO}$ films previously [26]. A loss of crystallinity occurs above $3 \mathrm{wt} \%$ In doping that may be associated to the stress originated due to the difference in ionic radii of $\mathrm{Zn}$ and $\mathrm{In}$. The ionic radius of $\mathrm{In}^{3+}$ is around $0.81 \AA$ and that of $\mathrm{Zn}^{2+}$ is $0.74 \AA$. This leads to an increase in the lattice strain shown in table 1.

FESEM images of the undoped and the In-doped $\mathrm{Zn}(\mathrm{O}, \mathrm{S})$ films are shown in figure 2a-f. Surface morphology of the films is found to depend strongly on dopant concentration and annealing conditions. The undoped $\mathrm{Zn}(\mathrm{O}, \mathrm{S})$ film shows a structure consisting of 3-dimensional grains with a average size of $50 \mathrm{~nm}$ (figure 2a). As the In-doping concentration increases from 1 to $3 \mathrm{wt} \%$, wedge-like morphologies appeared, which is evident from figure $2 \mathrm{~b}$ and $\mathrm{c}$, respectively. This subsequently changes to 2-dimensional flake-like morphologies in the sample having $5 \mathrm{wt} \%$ of In (figure $2 \mathrm{~d}$ ). This morphological evolution is consistent with the XRD observation that confirms a $c$-axis-oriented structure with preferential (002) orientations. It is reported that a dopant can influence the growth kinetics during deposition process, which affects the grain structure [25] and is evident from the cluster 


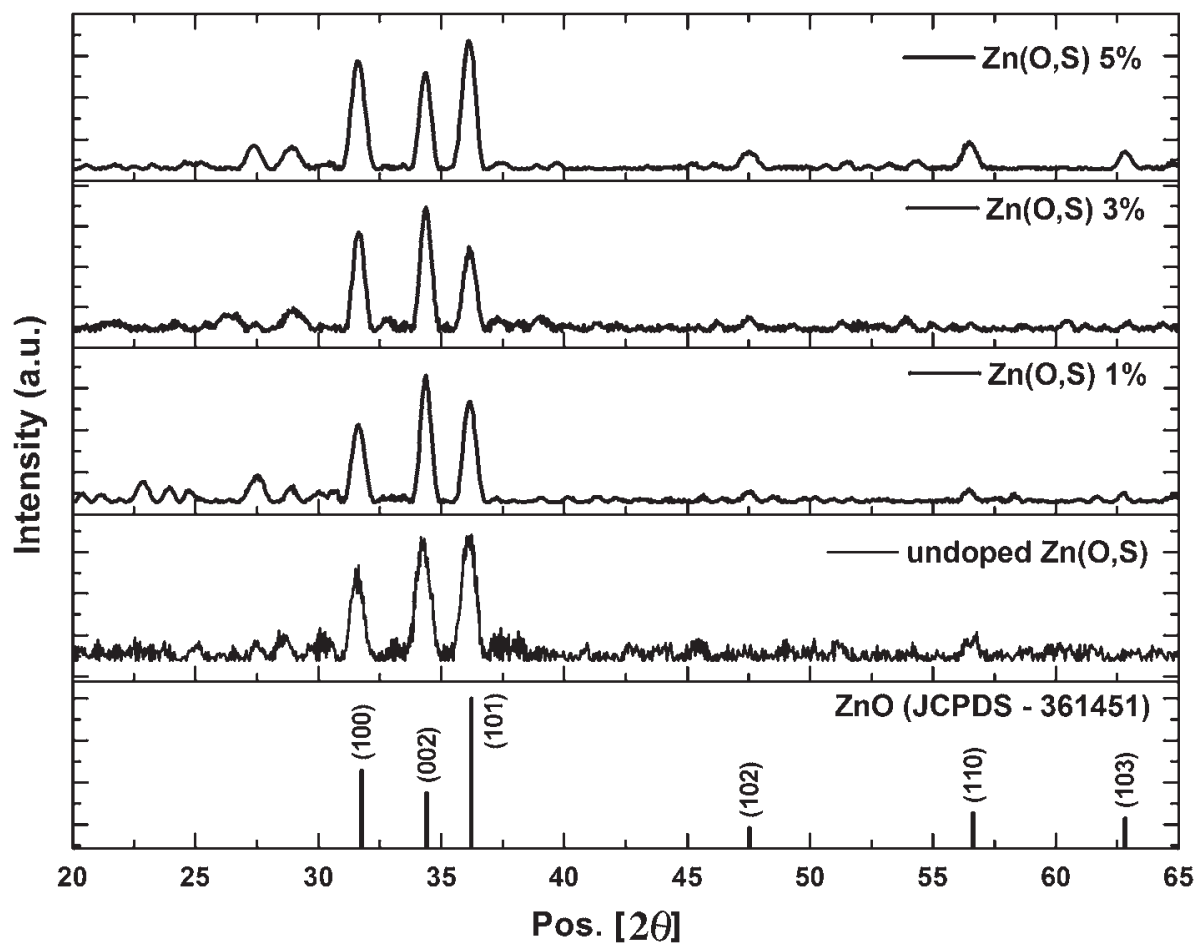

Figure 1. XRD patterns of $\mathrm{Zn}(\mathrm{O}, \mathrm{S})$ thin films on glass with variations in In-doping concentration $(1,3$ and $5 \mathrm{wt} \%)$.

Table 1. Crystallite size and strain variations with In-doping variations.

\begin{tabular}{lccc}
\hline $\begin{array}{c}\text { Indium } \\
\text { concentration } \\
(\mathrm{wt} \%)\end{array}$ & $\begin{array}{c}\text { Crystallite } \\
\text { size }(\AA)\end{array}$ & Strain $(\%)$ & $\begin{array}{c}\text { X-ray diffraction inten- } \\
\text { sity ratio: } I(002) / I(002) \\
+I(100)\end{array}$ \\
\hline 0 & $208 \pm 10.4$ & $0.62 \pm 0.01$ & 0.374 \\
1 & $124 \pm 6.2$ & $1.04 \pm 0.03$ & 0.524 \\
3 & $158 \pm 7.9$ & $0.81 \pm 0.02$ & 0.457 \\
5 & $179 \pm 8.9$ & $0.91 \pm 0.03$ & 0.286 \\
\hline
\end{tabular}

formation in as-prepared $1 \mathrm{wt} \%$ In-doped $\mathrm{Zn}(\mathrm{O}, \mathrm{S})$ sample. As the In concentration increases, a 2D growth of cluster converts into edge-like microstructure. With further increment of In concentration, (100) planes grew at the expense of (002) planes, giving rise to a greater 2D morphologies with flake-like structures. In the present study, two different types of annealing were performed to investigate not only the microstructural transformation, but also to see the change in the vacancy sites. It is observed that annealing atmosphere directly affects the grain boundaries. Due to a reduction of strain during annealing in air, wedge- or flake-like structures contract from their sides to produce compact film with reduced porosity and increased packing density (figure $2 \mathrm{e}$ ). However, upon annealing at same temperature in argon atmosphere, grain boundaries are reduced and the films become more compact as shown in figure $2 \mathrm{f}$.

In this case, to get finer details of microstructure, transmission electron microscopy (TEM) was conducted over the collected particles by removing the film ultrasonically in ethanol. Figure $2 \mathrm{~g}$ shows TEM image of the $3 \mathrm{wt} \%$ In-doped $\mathrm{Zn}(\mathrm{O}, \mathrm{S})$ after argon annealing. A compact flake-like morphology (with average dimension of $30 \mathrm{~nm}$ ) is observed in this case. The HRTEM image reveals crystalline nature of $\mathrm{In}: \mathrm{Zn}(\mathrm{O}, \mathrm{S})$ as shown in figure $2 \mathrm{~h}$, where a localized crystallanity of the flake is evident. The inter-planar distance of the crystal fringe in this region is estimated to be $2.5 \AA$ that agrees well with the observed $d$-spacing of the preferentially orientated crystal plane (002) of the hexagonal wurtzite structure of $\mathrm{Zn}(\mathrm{O}, \mathrm{S})$ as observed in the XRD spectra.

Figure 3 shows the AFM micrographs of topographic variation in the un-doped as well as $3 \mathrm{wt} \%$ In-doped $\mathrm{Zn}(\mathrm{O}, \mathrm{S})$ thin films. It is clear from the figure that the particle size and uniformity of the film are found to be affected by the process of doping (no. of processes you have adopted during the film making using dopant) and annealing conditions. The distribution of the particles are almost uniform in the $\mathrm{Zn}(\mathrm{O}, \mathrm{S})$ film, however, in the case of doped sample, the particle distribution becomes sharper and centred at a lower value after the doping. The average particle size decreases from $207 \mathrm{~nm}$ for $\mathrm{Zn}(\mathrm{O}, \mathrm{S})$ to $183 \mathrm{~nm}$ for $\mathrm{In}$-doped $\mathrm{Zn}(\mathrm{O}, \mathrm{S})$. The reduction in the particle size of In: $\mathrm{Zn}(\mathrm{O}, \mathrm{S})$ agrees well with previously reported In: $\mathrm{ZnO}$ prepared by sol-gel techniques with indium content up to $2 \mathrm{wt} \%$ [27]. Furthermore, the incorporation of In also reduces the root mean square (RMS) roughness from 0.34 to $0.1 \mu \mathrm{m}$ due to the reduction in particle size, which is consistent with other sol-gel derived In:ZnO films [28]. The AFM topographs also show that the distinct grain boundaries 

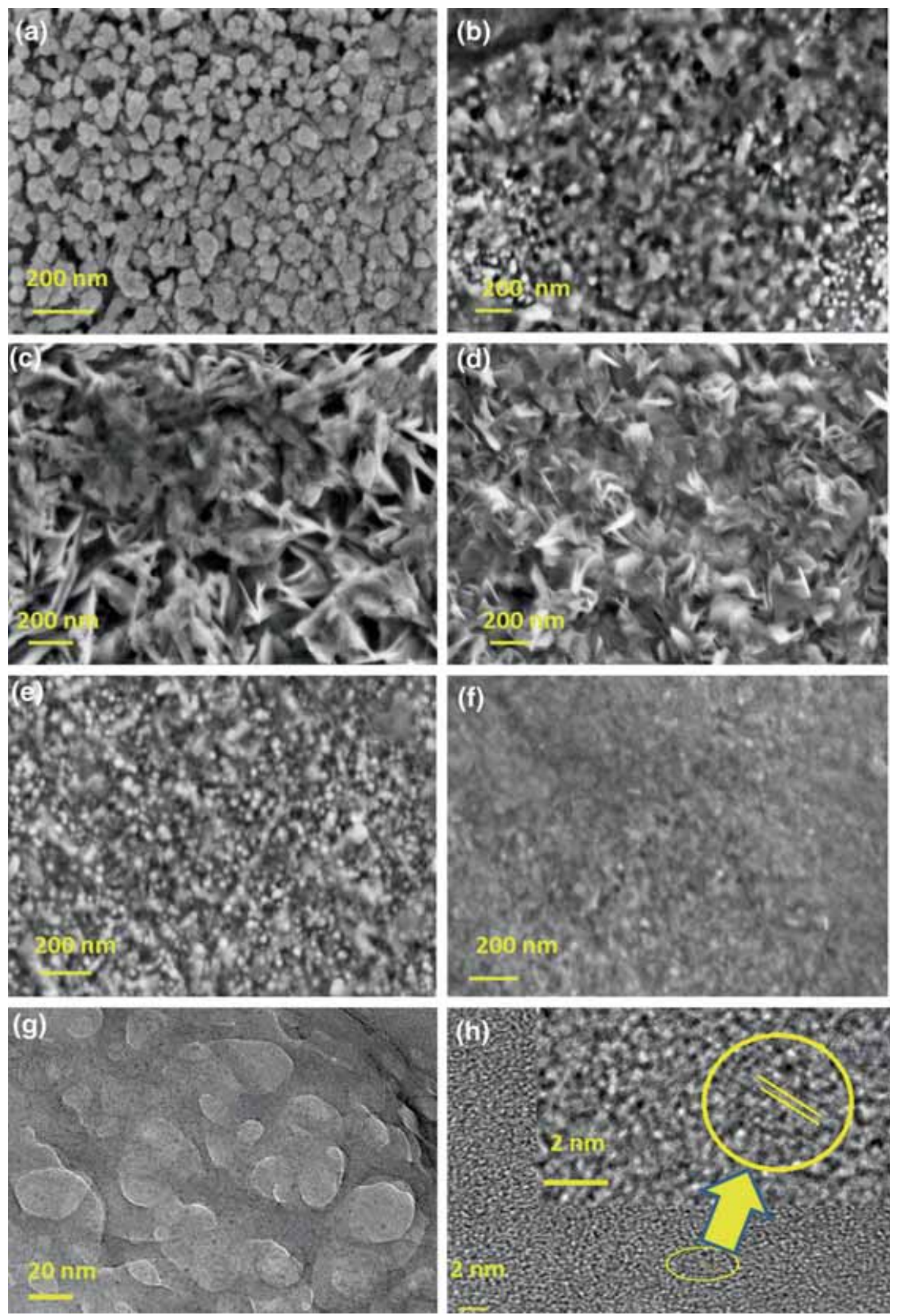

Figure 2. (a-f) FESEM micrographs exhibiting morphological variations of In-doped $\mathrm{Zn}(\mathrm{O}, \mathrm{S})$ with variation in doping and annealing conditions: (a) undoped $\mathrm{Zn}(\mathrm{O}, \mathrm{S})$, (b) $1 \mathrm{wt} \% \operatorname{In}: \mathrm{Zn}(\mathrm{O}, \mathrm{S})$, (c) $3 \mathrm{wt} \% \mathrm{In}: \mathrm{Zn}(\mathrm{O}, \mathrm{S})$, (d) 5 wt $\%$ In: $\mathrm{Zn}(\mathrm{O}, \mathrm{S}),(\mathbf{e})$ air-annealed and (f) Ar-annealed films. (g-h) High-resolution TEM images of Ar-annealed 3 wt $\%$ $\mathrm{In}: \mathrm{Zn}(\mathrm{O}, \mathrm{S})$ sample showing crystalline domain. 

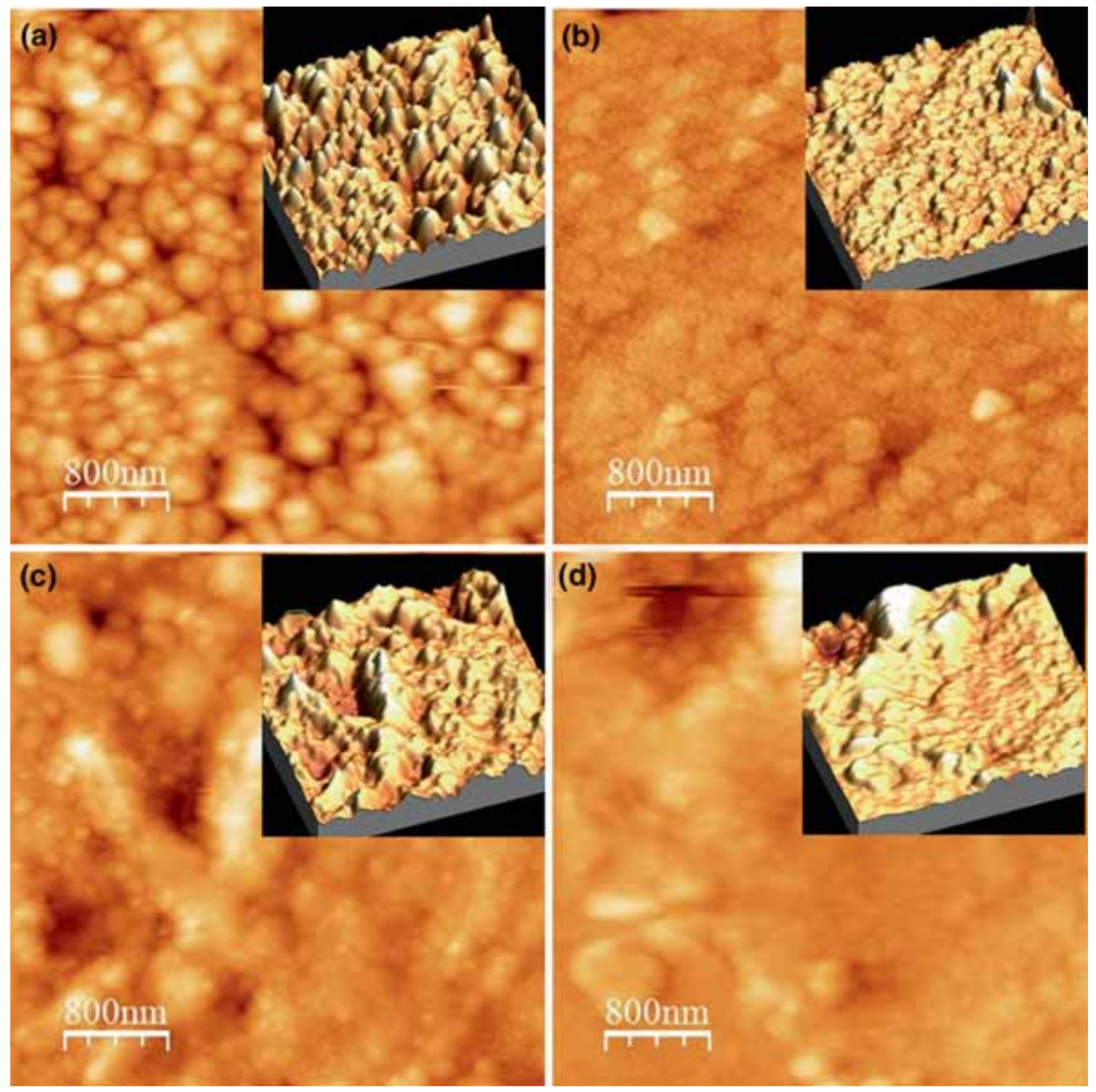

Figure 3. AFM images of (corresponding histograms as inset) (a) undoped- $\mathrm{Zn}(\mathrm{O}, \mathrm{S}) 20 \%$, (b) In-doped-Zn(O,S) $20 \%$, (c) air-annealed In-doped-Zn(O,S) $20 \%$ and (d) argon-annealed In-doped-Zn(O,S) $20 \%$.

are less prominent after annealing the doped film in air and almost absent in the case of annealing in Ar atmosphere where the film shows nearly well-connected grains.

\subsection{Optical studies}

The optical characterizations are done to find the light transmission properties and to determine the band gaps of the films. An optimization of sulphur content was done in $\mathrm{Zn}(\mathrm{O}, \mathrm{S})$ before doping the indium. Thiourea was used as a source of sulphur in $\mathrm{Zn}(\mathrm{O}, \mathrm{S})$, the weight fraction of which was varied between $0(\mathrm{ZnO})$ and $100 \%(\mathrm{ZnS})$ to obtain its band gap most suitable for a chalcopyrite solar cells. The energy band gap was determined from transmittance values by Tauc's method as described in later part of this section. With the variation of sulphur, a band-bowing effect was observed in the $\mathrm{Zn}(\mathrm{O}, \mathrm{S})$ system $\left(E_{\mathrm{g}}\right.$ varied between 3.3 and $3.6 \mathrm{eV}$ with a minimum of $2.8 \mathrm{eV}$ at $20 \mathrm{wt} \%$ of sulphur as shown in figure 4a). In the formation of heterojunction with the absorber, such as $\mathrm{Cu}_{2} \mathrm{ZnSn}(\mathrm{S} / \mathrm{Se})_{4}(\mathrm{CZTS})$ or $\mathrm{CuIn}(\mathrm{S} / \mathrm{Se})_{2}$ (CIS), a wider band gap buffer layer causes larger conduction band offset (CBO) and therefore, $\mathrm{Zn}(\mathrm{O}, \mathrm{S})$ with $10-20 \mathrm{wt} \%$ sulphur is expected to produce a minimum CBO. Therefore, the In-doping is done in the $\mathrm{Zn}(\mathrm{O}, \mathrm{S})$ with the sulphur content restricted at $20 \mathrm{wt} \%$. The effect of doping on the optical transmittance spectra and the band gap of $\mathrm{Zn}(\mathrm{O}, \mathrm{S})$ films were investigated in the wavelength range from 300 to $1100 \mathrm{~nm}$ as shown in figure $4 \mathrm{~b}$. The transmittance of all the films is high $(\sim 85 \%)$ in the visible photon energies. The absorption coefficient $(\alpha)$ of the films was determined from the relationship,

$$
\alpha=-\frac{1}{d} \ln \frac{T}{(1-R)^{2}}
$$



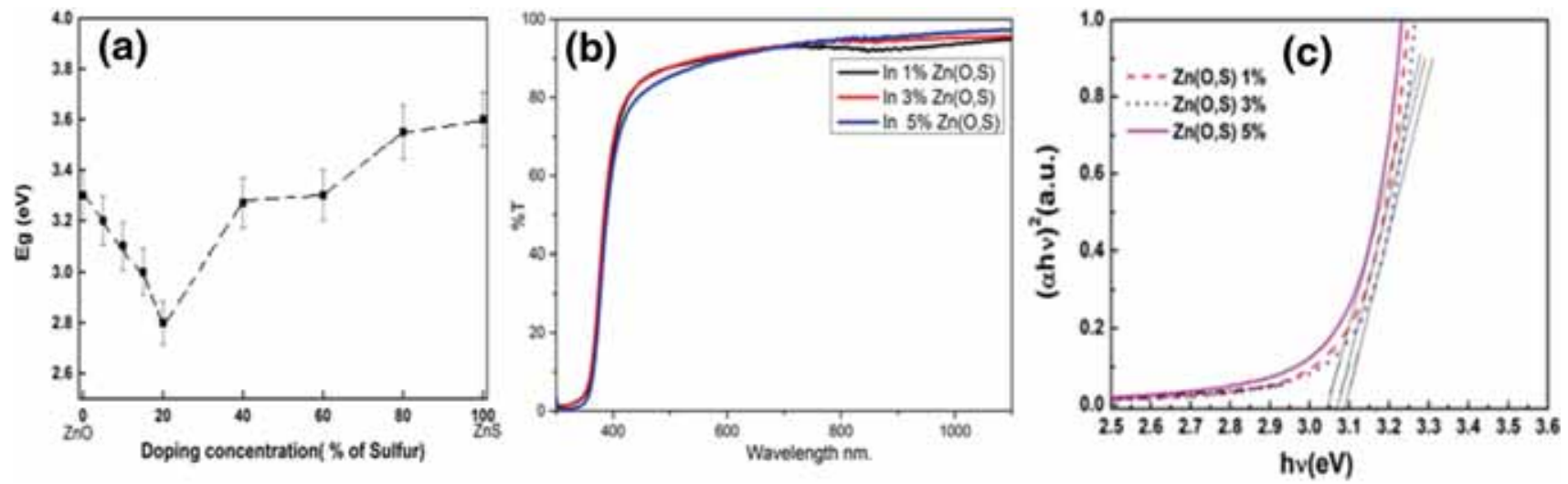

Figure 4. (a) Variation in optical band gap of $\mathrm{Zn}(\mathrm{O}, \mathrm{S})$ for various sulphur contents, (b) optical transmission spectra of sprayed In-doped $\mathrm{Zn}(\mathrm{O}, \mathrm{S}) 10 \%$ thin films on glass substrate with variation in indium content and (c) Tauc's plot demonstrating the direct band gaps of In-doped $\mathrm{Zn}(\mathrm{O}, \mathrm{S}) 10 \%$.

where $d, T$ and $R$ are the thickness, transmittance and reflectance, respectively. The band gap energy for each of the film is determined according to Tauc's method [29] by plotting $(\alpha h \gamma)^{2} v s$. the photon energy $h \gamma$ and extrapolating the linear region to the energy axis, which is shown in figure 4c. For direct allowed optical transition, it follows the equation:

$$
\alpha h \gamma=A\left(h \gamma-E_{\mathrm{g}}\right)^{1 / 2},
$$

where $E_{\mathrm{g}}$ is the band gap.

It is interesting to note that all the tested samples followed equation (2), which confirms the existence of direct band gap. The estimated optical band gap for $\mathrm{ZnO}$ was $3.33 \pm 0.01 \mathrm{eV}$ and it decreased to $2.8 \pm 0.01 \mathrm{eV}$ as the sulphur concentration was increased to $20 \mathrm{wt} \%$. In the formation of heterojunction with the absorber, such as $\mathrm{Cu}_{2} \mathrm{ZnSn}(\mathrm{S} / \mathrm{Se})_{4}$ (CZTS) or $\mathrm{CuIn}(\mathrm{S} / \mathrm{Se})_{2}$ (CIS), a wider band gap buffer layer causes larger band offset and therefore, $\mathrm{Zn}(\mathrm{O}, \mathrm{S})$ with $10-20 \mathrm{wt} \%$ sulphur exhibits band gap in the range of 3.1-2.8 eV, which may be useful in thin film photovoltaic. No noticeable blue shift in the band gap was observed by the In-doping in the range of $1-5 \mathrm{wt} \%$, indicating that the free carrier concentration in this film is not high enough to cause Burstein-Moss kind shift of band gap in $\mathrm{Zn}(\mathrm{O}, \mathrm{S})$ and the Fermi level should still to be located within the band gap [30].

\subsection{Electrical properties}

The variations of room temperature carrier concentration, resistivity and mobility of undoped and In-doped $\mathrm{Zn}(\mathrm{O}, \mathrm{S})$ thin films are shown in figure 5. The effect of annealing condition is also presented in figure 5. It is found that the carrier concentration was found to reduce by nearly one order magnitude, while doping with In (figure 5). However, in the undoped as well as doped $\mathrm{Zn}(\mathrm{O}, \mathrm{S})$ film, it was found to be widely different in the air and argon annealing conditions, where it was in the range of $10^{14}$ and $10^{18}-10^{19} \mathrm{~cm}^{-3}$, respectively.
On the other hand, the carrier mobility remained high when the film sample was annealed in air, although its resistivity was large for low indium concentrations. Based on the above observations, the electrical properties of the In-doped $\mathrm{Zn}(\mathrm{O}, \mathrm{S})$ may be described in terms of the oxygen vacancies, which play deterministic role in the intrinsic doping of $\mathrm{ZnO}$. The annealing enhances the grain growth and brings down the barrier heights across the grain boundaries in general. The annealing in the inert atmosphere such as in the presence of argon helps the indium atoms to diffuse across the grain boundaries more effectively that results in an increased number of free charge carriers and thus, decreases the resistivity [31].

A high density of defects across the grain boundaries is usually observed in the films processed from aqueous solution routes. These defects trap the hydroxyl ions in large numbers and those in turn capture electrons from bulk and the system degeneracy occurs. According to this charge trapping model, large potential barrier would exist across the grain boundaries [32], which may be reduced through annealing. By the annealing in air, oxygen is chemisorbed on the surface of $\mathrm{Zn}(\mathrm{O}, \mathrm{S})$ causing the formation of strong surface depletion of carriers as these chemisorbed oxygen atoms capture electrons from the bulk and form $\mathrm{O}_{2}^{-}$ions. This annealing condition keeps the bulk concentration in the range of $10^{13}-10^{15} \mathrm{~cm}^{-3}$. At this temperature, the resistivity is quite large due to the formation of barriers from the chemisorbed oxygens. The incorporation of indium helps to reduce the resistivity by indirectly increasing the mobility of the electrons in the film. Initially, In-incorporated films (1-3 wt \%) show slower mobility than the film without indium $\left(17.2 \mathrm{~cm}^{2} \mathrm{~V}^{-1} \mathrm{~s}^{-1}\right)$, which may be due to the increased lattice disorder introduced by indium $[27,28]$. However, the conductivity of the film is improved by five orders when annealed under argon atmosphere. The improvement in the conductivity may be attributed to both the reduction in the grain boundary scattering from the large grain size, their connectivity and a reduction of oxygen and hydroxyl group related defects across the grain boundaries. 


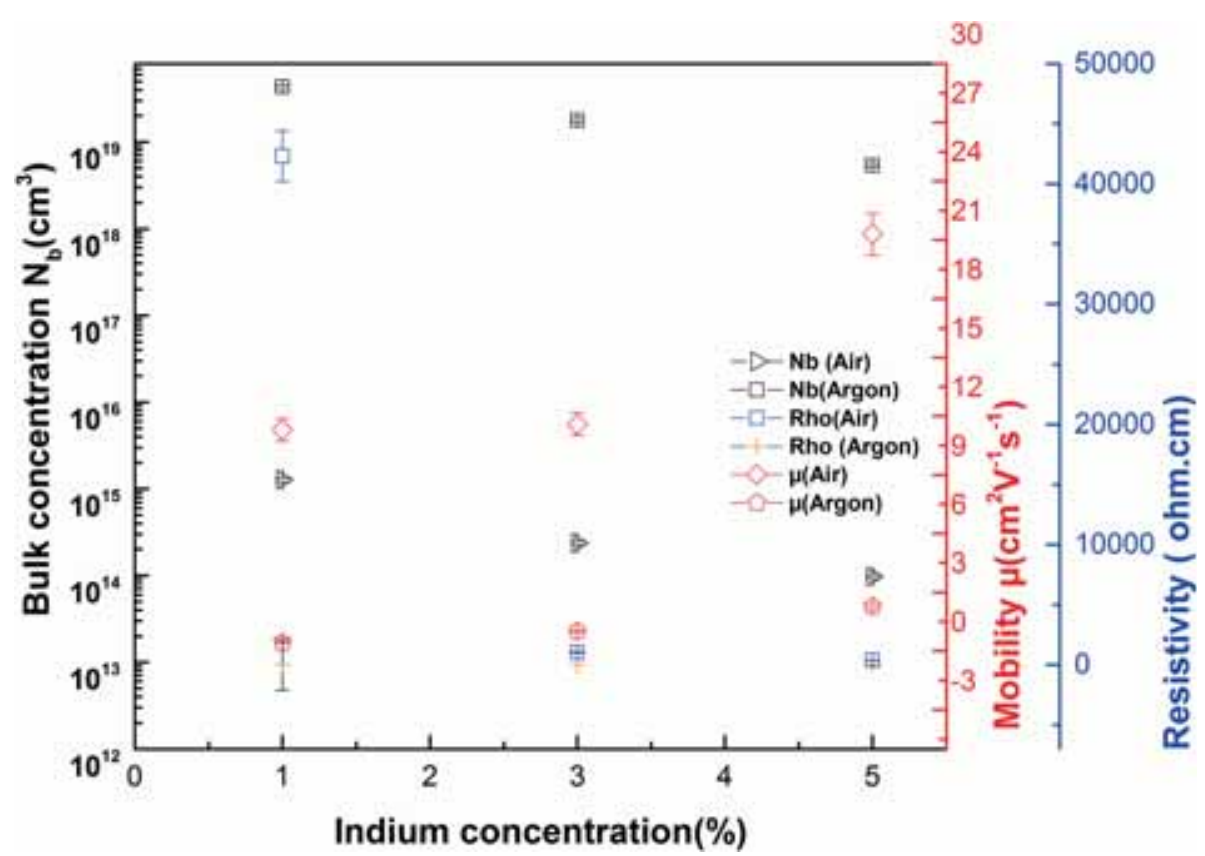

Figure 5. Electrical properties of In-doped $\mathrm{Zn}(\mathrm{O}, \mathrm{S})$ for different annealing conditions.

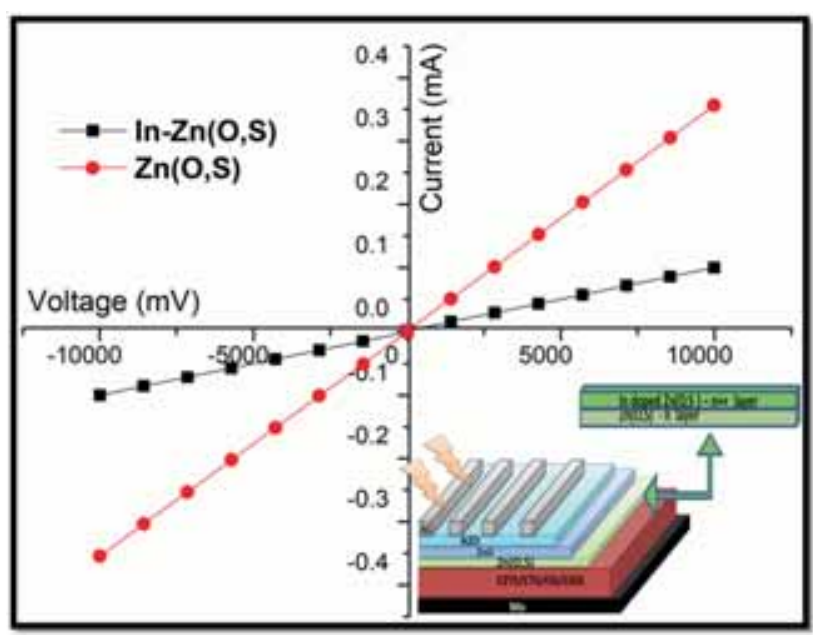

Figure 6. Electrical characteristics (current-voltage behaviour) of $\mathrm{Zn}(\mathrm{O}, \mathrm{S})$ and In-doped $\mathrm{Zn}(\mathrm{O}, \mathrm{S})$ film obtained by Hall measurement effect (where In-doped $\mathrm{Zn}(\mathrm{O}, \mathrm{S})$ exhibits good ohmic characteristics).

To evaluate the electron membrane behaviour of the In-doped $\mathrm{Zn}(\mathrm{O}, \mathrm{S})$, its current voltage characteristics were recorded as shown in figure 6 and compared with the undoped $\mathrm{Zn}(\mathrm{O}, \mathrm{S})$. By the incorporation of In in $\mathrm{Zn}(\mathrm{O}, \mathrm{S})$, a better ohmic behaviour is established as compared to $\mathrm{Zn}(\mathrm{O}, \mathrm{S})$. For a better device performance, ohmic behaviour of the buffer and the window layer are important requirements and therefore, Indoped $\mathrm{Zn}(\mathrm{O}, \mathrm{S})$ can be a good alternative window layer to the $\mathrm{Zn}(\mathrm{O}, \mathrm{S})$-based buffer. Additional advantage of such window layer is a small band discontinuity with the buffer layer.

\section{Conclusions}

In-doped $\mathrm{Zn}(\mathrm{O}, \mathrm{S})$ films within the doping range of 1-5 wt $\%$ were prepared in situ by the spray pyrolysis process. A doping in the rage of $1-3 \mathrm{wt} \%$ of indium is found to enhance carrier concentration to the level of degeneracy $\left(10^{19} \mathrm{~cm}^{-3}\right)$, which was reduced to the level of $10^{14}-10^{15} \mathrm{~cm}^{-3}$ by annealing in air, much suitable as a buffer layer. After annealing in Ar atmosphere, the films show $c$-axis preferred orientation and the conductivity improves by five orders, which may be useful as electron membrane layer between buffer layer and TCO layers applied in the thin film solar cells with Cd-free alternative buffer materials.

\section{Acknowledgements}

We acknowledge Solar Research and Development Centre (SRDC) of Pandit Deendayal Petroleum University, Project no. 2, for funding the research. We are grateful to Prof Utpal Joshi of Gujarat University for providing AFM facilities. Dr D N Srivastava from Central Salt and Marine Chemical Research Institute (CSMCRI) is thankfully acknowledged for performing TEM imaging.

\section{References}

[1] Godlewski M, Guziewicz E, Kopalko K, Łuka G, Łukasiewicz M, Krajewski T et al 2011 Low Temp. Phys. 37235

[2] Xu C, Sun X W, Yuen C, Chen B, Yu S and Dong Z L 2005 Appl. Phys. Lett. 86011118 
[3] Battaglia C, Escarré J, Söderström K, Charrière M, Despeisse M, Haug F-J et al 2011 Nat. Photon. 5535

[4] Nunes P, Fortunato E, Tonello P, Fernandes F B, Vilarinho P and Martins R 2002 Vacuum 64281

[5] Pearton S, Norton D, Ip K, Heo Y and Steiner T 2004 J. Vac. Sci. Technol. B 22932

[6] Avrutin V, Silversmith D J and Morkoç H 2010 Proc. IEEE 98 1269

[7] Yousefi R and Kamaluddin B 2010 Solid State Sci. 12252

[8] Deulkar S H, Huang J-L and Neumann-Spallart M $2010 \mathrm{~J}$. Electron. Mater. 39589

[9] Fan X, Shen Z, Lu Y and Kuo J-L 2009 New J. Phys. 11093008

[10] Thankalekshmi R R and Rastogi A 2012 J. Appl. Phys. 112 063708

[11] Sun J, Nalla V, Nguyen M, Ren Y, Chiam S Y, Wang Y et al 2015 Sol. Energy 115396

[12] Bernede J, Barreau N, Marsillac S and Assmann L 2002 Appl. Surf. Sci. 195222

[13] Mangan N M, Brandt R E, Steinmann V, Jaramillo R, Yang C, Poindexter J R et al 2015 J. Appl. Phys. 118115102

[14] Park H H, Heasley R and Gordon R G 2013 Appl. Phys. Lett. 102132110

[15] Park H H, Jayaraman A, Heasley R, Yang C, Hartle L, Mankad R et al 2014 Appl. Phys. Lett. 105202101

[16] Jun M-C, Park S-U and Koh J-H 2012 Nanoscale Res. Lett. 71

[17] Benramache S, Benhaoua B and Bentrah H 2013 J. Nanostruct. Chem. 31
[18] Palimar S, Bangera K V and Shivakumar G 2013 Appl. Nanosci. 3549

[19] Gonçalves G, Elangovan E, Barquinha P, Pereira L, Martins R and Fortunato E 2007 Thin Solid Films 5158562

[20] Aktaruzzaman A, Sharma G and Malhotra L 1991 Thin Solid Films 19867

[21] Li Y, Tompa G, Liang S, Gorla C, Lu Y and Doyle J 1997 J. Vac. Sci. Technol. A 151063

[22] Patil P S 1999 Mater. Chem. Phys. 59185

[23] Tang W and Cameron D C 1994 Thin Solid Films 238 83

[24] Rashidi N, Kuznetsov V L, Dilworth J R, Pepper M, Dobson P J and Edwards P P 2013 J. Mater. Chem. C 16960

[25] Thomson I, Solookinejad Gh and Jabbari M 2011 J. Appl. Sci. 112954

[26] Girtan M, Socol M, Pattier B, Sylla M and Stanculescu A 2010 Thin Solid Films 519573

[27] Ubale A and Deshpande V 2010 J. Alloys Compd. 500 138

[28] You H-C 2013 Int. J. Electrochem. Sci. 830

[29] Sharma J, Saint G, Goyal N and Tripathi S 2007 J. Optoelectron. Adv. Mater. 93194

[30] Lai H H-C, Basheer T, Kuznetsov V L, Egdell R G, Jacobs R M, Pepper M et al 2012 J. Appl. Phys. 112083708

[31] Ikhmayies S J, El-Haija N M A and Ahmad-Bitar R N 2010 Phys. Scr. 81015703

[32] Seto J Y 1975 J. Appl. Phys. 465247 